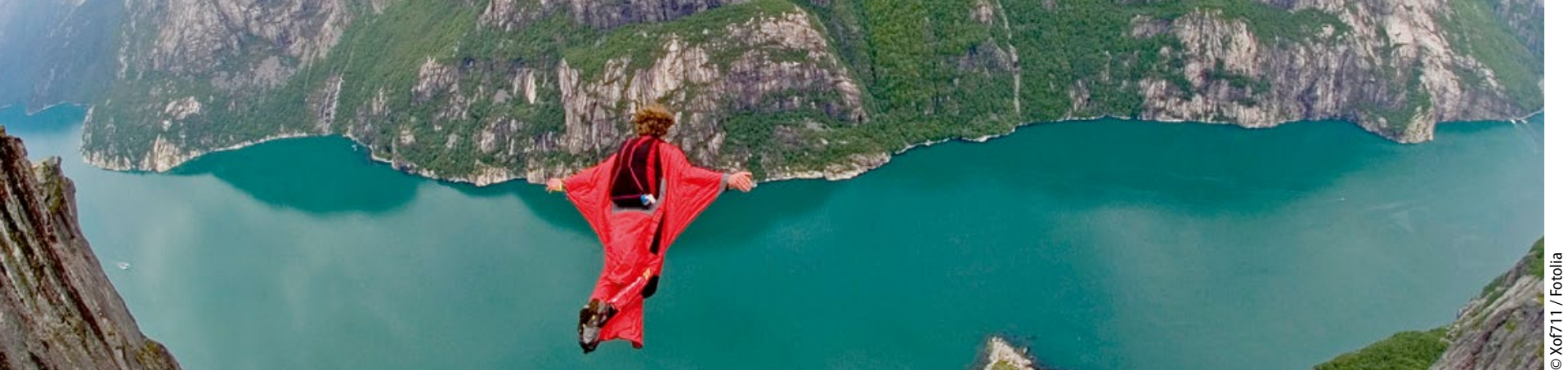

\title{
Extremsport
}

\section{Kalkulierter Wahnsinn}

\author{
Man muss schon etwas verrückt sein, um von Italien ans Nordkap zu rennen oder um mit einem \\ Wingsuit durch eine Felsspalte zu rauschen. Aber letztlich unterscheiden sich Extremsportler \\ psychisch nicht so sehr von anderen Menschen - die meisten wissen genau, was sie tun.
}

_ Ist Uli Emanuele völlig durchgeknallt? Der 29-jährige Südtiroler hat im Juli 2015 einen der waghalsigsten Basejumps riskiert. Mit einem Wingsuit, einer Art Fledermauskostüm, das beim Sturz aus großer Höhe einen rasanten Gleitflug ermöglicht, ist er mit über $100 \mathrm{~km} / \mathrm{h}$ durch eine nur zwei Meter breite Felsspalte gerast. Eine falsche Bewegung, ein Windstoß, und es wäre nicht viel von ihm übrig geblieben. Viele halten Hochrisikosportler wie Emanuele für lebensmüde und eher wahnsinnig als waghalsig. Doch der Wahnsinn hat hier Kalkül. Basejumper sind genauso wenig verrückt wie die meisten von uns. Im Gegenteil: Sie lassen sich von Risiken nicht verrückt machen, sondern versuchen, sie zu beherrschen.

\section{Der Gefahr bewusst}

Professionelle Hochrisikosportler sind sich der Gefahren durchaus bewusst, sagte der Innsbrucker Sportpsychologe Prof. Martin Kopp. Sie wissen, dass ein kleiner Fehler tödlich ist, sie leugnen das Verletzungsrisiko nicht und zeigen auch keinen unrealistischen Optimismus, nach dem Motto „mir kann das aber nicht passie- ren“. Darauf deuten neuere Untersuchungen hin. Früher wurde als Motivation oft nur der Nervenkitzel, das „Sensation Seeking " gesehen. Mittlerweile ergibt sich ein komplexeres Bild, das auch die Steigerung des Selbstwerts und des Identitätsgefühls berücksichtigt. Risikosport kann auch als Wunsch verstanden werden, aus einem überzivilisierten Leben voll Langweile und Leere auszubrechen. Nicht zu unterschätzen sind dabei die sozialen Medien: Die modernen Helden finden ihr Publikum über Videos auf Youtube und Facebook - die Helmkamera ist heute ein unverzichtbares Accessoire in der Szene. Selbstdarstellung, so Kopp, ist oft wichtiger als der Nervenkitzel. Das Video von Emanueles Flug wurde über fünf Millionen Mal geklickt (https://www.youtube. com/watch?v=-C_jPcUkVrM).

\section{Gut trainierte Leidensfähigkeit}

$\mathrm{Zu}$ einer anderen Gruppe von Extremsportlern gehören Menschen wie der griechische Ultramarathonläufer Yiannis Kouros. Er schafft in sechs Tagen zu Fuß 1.030 Kilometer. Das sind täglich über 170 Kilometer oder etwas mehr als vier Ma- rathonstrecken. Da fragt sich natürlich, ob das für den Köper noch gesund ist.

Doch offenbar gehen die meisten der Extrem-Ausdauersportler genauso professionell vor wie Hochrisikoathleten: Durch hartes Training schaffen sie selbst unmenschlich anmutende Strecken in der Regel ohne bleibende Schäden. Darauf deutet eine Untersuchung von mehr als 30 Probanden beim Transeurope Footrace im Jahr 2009. Bei diesem Rennen liefen die Sportler ohne einen Tag Pause in zwei Monaten von Bari an der Adria ans Nordkap - im Schnitt $70 \mathrm{~km}$ am Tag. Da hat der Körper praktisch keine Chance, sich adäquat zu erholen. Auch das Gehirn zeigte in gewissen Bereichen Volumenreduktionen, wie Aufnahmen in einem MRT-Scanner ergaben. Einige Zeit nach dem Rennen ließen sich jedoch keine Auffälligkeiten mehr nachweisen, so Prof. Andreas Ströhle, Charité Berlin. Allerdings scheinen Ultramarathonläufer deutlich weniger schmerzempfindlich zu sein. In einem Test konnten sie ihre Hand dreimal so lange in Eiswasser baden wie Ungeübte.

- Thomas Müller

- DGPPN-Kongress, Berlin, 25.-28. November 2015. 